\title{
Achievements in Research and Teaching-Investigating the Effect of Age and Gender
}

\author{
Eyal Eckhaus ${ }^{1} \&$ Nitza Davidovitch ${ }^{2}$ \\ ${ }^{1}$ Department of Economics and Business Administration, Ariel University, Ariel, Israel \\ ${ }^{2}$ Head of Academic Quality and Assessment, Head of Teacher Training Program, Ariel University, Israel \\ Correspondence: Eyal Eckhaus, Department of Economics and Business Administration, Ariel University, Ariel, \\ Israel. E-mail: eyale@ariel.ac.il
}

Received: October 21, 2020 Accepted: November 20, 2020 Online Published: November 23, 2020

doi:10.5539/jel.v9n6p121 URL: https://doi.org/10.5539/jel.v9n6p121

\begin{abstract}
Purpose. This study deals with the research and teaching achievements of faculty members as affected by demographics. The topic of age of employment, as well as age of retirement, is one that occupies modern society, both in research and with regard to the significance of age for the labor world in practice. Gender-related differences regarding this issue have occupied the academic literature as well. In the current study we examined the impact of age and gender on research output (by number of citations) and satisfaction with teaching (by student survey scores).

Method. Empirical data on article citations and teaching surveys were gathered for 315 senior faculty members at Ariel University, Israel. Structural equation modeling was used to test the model's goodness-of-fit. Findings indicate that the higher the age of the faculty members the greater their output. The opposite is true of teaching surveys. Age appears to contribute to the number of article citations and less so to students' satisfaction with the teaching of senior faculty members. A sensitivity analysis was also performed. Men were found to have a higher number of citations than women.

Results and discussion. The research findings have practical meaning. The achievements of academic faculty members are undoubtedly age-dependent: seniority and experience contribute to research (number of citations) and do not contribute to teaching as measured by student satisfaction. The question is whether in the modern era, when quality of life and life expectancy are on the rise, there is room to breach the employment age limitations in academia, particularly for high academic producers, in light of their achievements.
\end{abstract}

Keywords: academic performance, measurement criteria, academic faculty

\section{Introduction}

\subsection{Research and Teaching Achievements of Faculty Members as Affected by Demographics}

Academic output is a very common topic in academia, both in Israel and elsewhere. Research output affects the prestige of the academic institution, of the faculty and the department, and of the faculty member (Almog \& Almog, 2020). In Israel, academic output has financial significance as well. For each article, academic institutions receive funding from the Council for Higher Education (CHE). Hence, output measures and examination of academic achievements is a hotly debated and charged topic.

About ten years ago, we explored the relationships between factors affecting the research and teaching excellence of faculty members and demographic measures such as age and gender. We found that the general excellence scores of male faculty members were $10 \%$ higher than those of female faculty members - in both research and teaching. This was particularly evident in male faculty members' higher excellence scores in research activities. In contrast, when assessing teaching, no significant gender-based differences were found (Davidovitch, Soen, \& Sinuani-Stern, 2011).

Teaching is an important component of academic work (Davidovitch \& Eckhaus, 2020; Eckhaus \& Davidovitch, $2019 \mathrm{~b}, 2019 \mathrm{c}$ ). With regard to the impact of age on excellence scores, younger faculty members (in the 35-44 age group) were perceived as those who devote all their time to their academic work. No significant differences were found in faculty members' general excellence scores by age group. Significant differences were found in 
the total excellence scores of faculty members between the young age group (35-44) and the other age groups, as measured by teaching surveys completed by students (Davidovitch \& Sinuani-Stern, 2014).

Moreover, age and gender are charged issues with regard to any attempt to link these measures to work in general and academic work in particular. This is evident in the Basic Law: Freedom of Occupation, which determines the natural right of all people to engage in any occupation or profession at will. This right was included in the international declaration on human rights pronounced by the UN in 1948. In Israel, the Basic Law: Freedom of Occupation was enacted in 1992, regulating the freedom of occupation as a supra-legal principle.

If so - in the 21st century, how do age and gender indices constitute measures of one's achievements in any occupation, all the more so in academia, a bastion of freedom of knowledge, breaching of limits, and creativity? How are these scientific values related to human limitations of age and gender?

\subsection{How Is Gender Associated with Scientific Achievements?}

The proportion of women in academia has been growing over the years, in numbers, in academic status, and in the diverse disciplines where they serve as faculty members. With regard to the association between gender and citations, there are different views. Previous studies found that men have a higher h-index than women, however these studies explored this only in specific disciplines such as psychology (Geraci, Balsis, \& Busch, 2015; Nosek et al., 2010), astronomy (Caplar, Racchella, \& Birrer, 2017), and neurosurgery (Tomei et al., 2014). In contrast, Borsuk and others (Borsuk, Budden, Leimu, Aarssen, \& Lortie, 2019) found no association between gender and number of citations, but they too explored this in the specific domain of ecology. In the current study we shall expand this field of research and explore it empirically across all faculties.

A report submitted to the Committee on the Status of Women and Gender Equality in Israel on behalf of the Knesset Research and Information Center (Lerer \& Avgar, 2018) indicated that in Israel women constitute less than one third (32\%) of all senior academic faculty members. Both in universities and in colleges, the proportion of women among all senior faculty members diminishes with the rise in rank. Women were more than half $(55 \%$ in universities and $53 \%$ in colleges) of faculty members with the rank of lecturer, more than one third (37\% in universities and $43 \%$ in colleges) of faculty members with the rank of senior lecturer, more than one quarter (29\% in universities and $27 \%$ in colleges) of faculty members with the rank of assistant professor, and less than one fifth (17\% in universities and $15 \%$ in colleges) of faculty members with the rank of full professor.

In addition, the proportion of women among all senior academic faculty members rose by 7 percentage points from 2003 to 2016. The rise was not similar in all academic ranks. The proportion of women among faculty members with the rank of lecturer rose by 12 percentage points, among faculty members with the rank of senior lecturer by 3 percentage points, among faculty members with the rank of assistant professor by 8 percentage points, and among faculty members with the rank of full professor by 5 percentage points (Lerer \& Avgar, 2018).

The total number of senior academic faculty members at universities, by full positions, rose from approximately 4,600 in 2003 to 4,900 in 2015 , a rise of about $6 \%$. But while the number of male faculty members dropped by about $2 \%$ during these years, women saw a rise of about $28 \%$, an average of about $2 \%$ per year. The proportion of women among all senior faculty members is not identical in all universities. In 2015, at most institutions the proportion of women among all senior faculty members was between $27 \%$ and $33 \%$, close to the proportion of women among all senior faculty at universities-30\%. At the Open University and Haifa University there was a relatively high proportion of women among senior faculty members $-46 \%$ and $42 \%$, respectively, and at the Technion there was a relatively low proportion-17\%. The data further indicate that in most institutions the proportion of women among new senior faculty members who began their work in 2015-2016 was higher than their proportion among all faculty members. The intake of women was particularly low at the Technion (9\%) and at the Weizmann Institute $(0 \%)$.

Furthermore, there are considerable differences in the proportion of women among senior academic faculty in different disciplines. In two disciplines women constitute the majority of academic faculty members: paramedical subjects - $63 \%$, and education - 55\% (in education women are the majority in all ranks, while in paramedical subjects, women are the majority in all ranks aside from full professor). In the social sciences and the humanities, the proportion of women among all faculty members is higher than in all disciplines in total, while in law, and particularly physics, engineering and mathematics, and computer science, the proportion of women is low-reaching $12 \%$ of faculty members in mathematics and computer science. Among students for all degrees and among $\mathrm{PhD}$ graduates, women constitute a conspicuous majority in education and in paramedical professions and a minority in physics, engineering and mathematics, and computer science (Lerer \& Avgar, 
2018).

Finally, despite the differences in the proportion of men and women between 2005 and 2015, in both points in time the same pattern is evident - a majority of women during academic studies, which diminishes in $\mathrm{PhD}$ studies. A male majority is evident among senior faculty members from the rank of senior lecturer and on, and it increases the more senior the rank. Hence, we see that the gender issue is very significant in the system of higher education in a country established on a foundation of excellence, both in the natural sciences and in the humanities and social sciences (CHE, 2015). The system of higher education has two main roles - on one hand to produce new knowledge, i.e., research, and on the other - to impart new and existing knowledge to the next generation, i.e., teaching. The academic faculty is in charge of these two domains. According to the Women's Equal Rights Law, 1951, it would have been expected to see men and women taking a similar part in this important work. But this is not so!

The academic system holds both internal responsibility for those within it, both men and women, and external responsibility for society. It must lead towards social improvement and fairness. Male and female graduates of the academic system - in all its stages - acquire experience, tools, and role models for the rest of their private life and for the social and public roles they will assume. All these will determine the future of society. Accordingly, a committee for promoting women in science and technology operates on behalf of the CHE-Planning and Budgeting Committee (PBC) and the National Council, beside the Ministry of Science, Technology, and Space, in order to clarify how to correct the distortions. In order to achieve this improvement, there is need for cooperation with the institutions of higher education-Equality is not achieved by mere good intentions, and the entire system must take responsibility and deal with the barriers encountered by women in their attempt to reach their full potential. This, of course, without lowering the excellence criteria.

Notably, a similar problem is evident in almost all countries. Recently, however, a considerable improvement is apparent in many developed countries, sometimes following interventions from above and affirmative action. The results show that affirmative action does not have a negative effect on the level of academic faculty. Hence, it seems that the system in Israel should also be stimulated in this direction.

\subsection{How Is Age Associated with Scientific Achievements?}

Among scientists, the "academic clock" was often set at age thirty, particularly by geniuses for whom this was indeed the actual state of affairs. For instance, Einstein said that anyone who has not made a contribution to science by the age of thirty will never do so. Similarly, the following poem is ascribed to British scientist Paul Dirac, who won the Nobel Prize in physics in 1933 at the age of thirty-one (Jones, 2010): "Age is of course a fever chill/that every physicist must fear/He's better dead than living still/When once he's past his thirtieth year".

However, beginning from the early twentieth century most countries experienced a dramatic rise in life expectancy. Accordingly, the urge to make haste and complete one's professional activity as early as possible diminished, while the duration of professional careers grew (Seidman, 2015). In addition, academics' training period increased in time. This means not only the formal aspect represented by the number of years needed to complete a degree but rather also an essential issue: In order to "stand on the shoulders of giants" it is necessary to command a huge amount of knowledge that is constantly growing. In a certain respect relevant for young people choosing a career, science is a complete contrast to hi-tech, where it is possible to see young entrepreneurs foregoing further academic studies, with their depth and width, in favor of innovative projects (Ibid., 2015). Moreover, factually, both scientific studies and anecdotal descriptions identify several interesting phenomena: one is the discrepancy between the different disciplines with regard to the age at which people reach their peak and how many years they were active previously. In some disciplines, particularly the non-scientific, researchers and artists reach their height at a relatively advanced age, after accumulating a sufficient extent of knowledge and breadth of vision.

Another phenomenon is the statistical curve whereby after several years of activity in a certain discipline the researcher indeed reaches a peak followed by a drop in achievements, but this is a slow decline that continues over several years. A third phenomenon is that, despite common opinion, most of the decline in cognitive capacity does not occur in one's sixties rather later on. Indeed, when academic institutions in the United States and the UK eliminated mandatory retirement in faculty members' seventh decade, it became rapidly apparent that some of the researchers indeed maintain their level of interest and drive and continue their activities far into the golden years. There is a significant rise in the age of academic faculty in Israel as well, although here the reason is non-intake of young faculty while the mandatory retirement age has remained constant.

The only study that examined the effect of age on the number of citations found that younger authors have a higher citation mean (Ayres \& Vars, 2000), but the study only reports this finding without explaining or 
investigating it. Their finding contradicts intuition and we hypothesize that our findings will prove the opposite. We are now in the early third decade of the 21 st century. Life expectancy has changed. Women are performing innovative work. No information is available on the age of faculty members. It remains unknown.

\subsection{Gender Effect on Achievement}

Carter, Smith and Osteen (2017) found that men had higher H-Index scores than women in all faculty ranks, especially at the Full Professor level. Panisch, Smith, Carter and Osteen (2017) found that the average h-index of male faculty was higher than women at the rank of lecturer and full professor. Women had a higher mean h-index than men at the rank of senior lecturer and associate professor. H-index means varied at the full professor level.

In contrast, Yang et al. (2019) found that women were not significantly inferior in academic performance, based on the H-Index measure. Mueller, Gaudilliere, Kin, Menorca and Girod (2016) found that the impact of publications, as measured by h-index and number of citations, was not consistently significantly different between the genders at any age or rank.

Jadidi, Karimi, Lietz and Wagner (2018) investigated academic collaboration, and found that women are less likely to adopt the collaboration patterns that are related with success.

Research hypotheses

H1. $A G E$ positively affects the total number of cites (TotalCites)

H2. $A G E$ positively affects cites from 2015 (Cites2015)

H3. $A G E$ positively affects $H$-Index

H4. AGE positively affects H-Index from 2015 (HIndex2015)

H5. AGE negatively affects students' teaching Survey

H6. Males have a higher number of citations than females.

\section{Method}

\subsection{Sample}

Empirical data on citations of articles and teaching surveys were gathered for 315 senior faculty members from Ariel University. Age ranged from 32-88. Age will be investigated in three major groups in the sensitivity analysis chapter. One hundred and two of the respondents were females, and 213 were males. The faculty members belonged to the following faculties: social sciences (105 respondents), health (29), nature (78), architecture (6), engineering (92), and medicine (5).

\subsection{Analysis}

We present several models and employ Structural Equation Modeling (SEM) to test the model's goodness-of-fit (Eckhaus, 2019a, 2019b; Eckhaus \& Sheaffer, 2019).

Model fit was estimated using CFI, TLI, RMSEA, and CMIN/DF. Values indicating good fit for CFI, TLI are above .95 (Liau et al., 2019). NFI above .95 (Kang \& Hustvedt, 2014), a CMIN/DF ratio lower than 3 is considered a good fit (Levy \& Eckhaus, 2020). RMSEA should be below .08 (Chan, Lonsdale, Ho, Yung, \& Chan, 2009). We added the faculties as controlled variables. The citation measures investigated were the Google citation indices.

\section{Results}

Figure 1 illustrates the model and standardized estimates. 


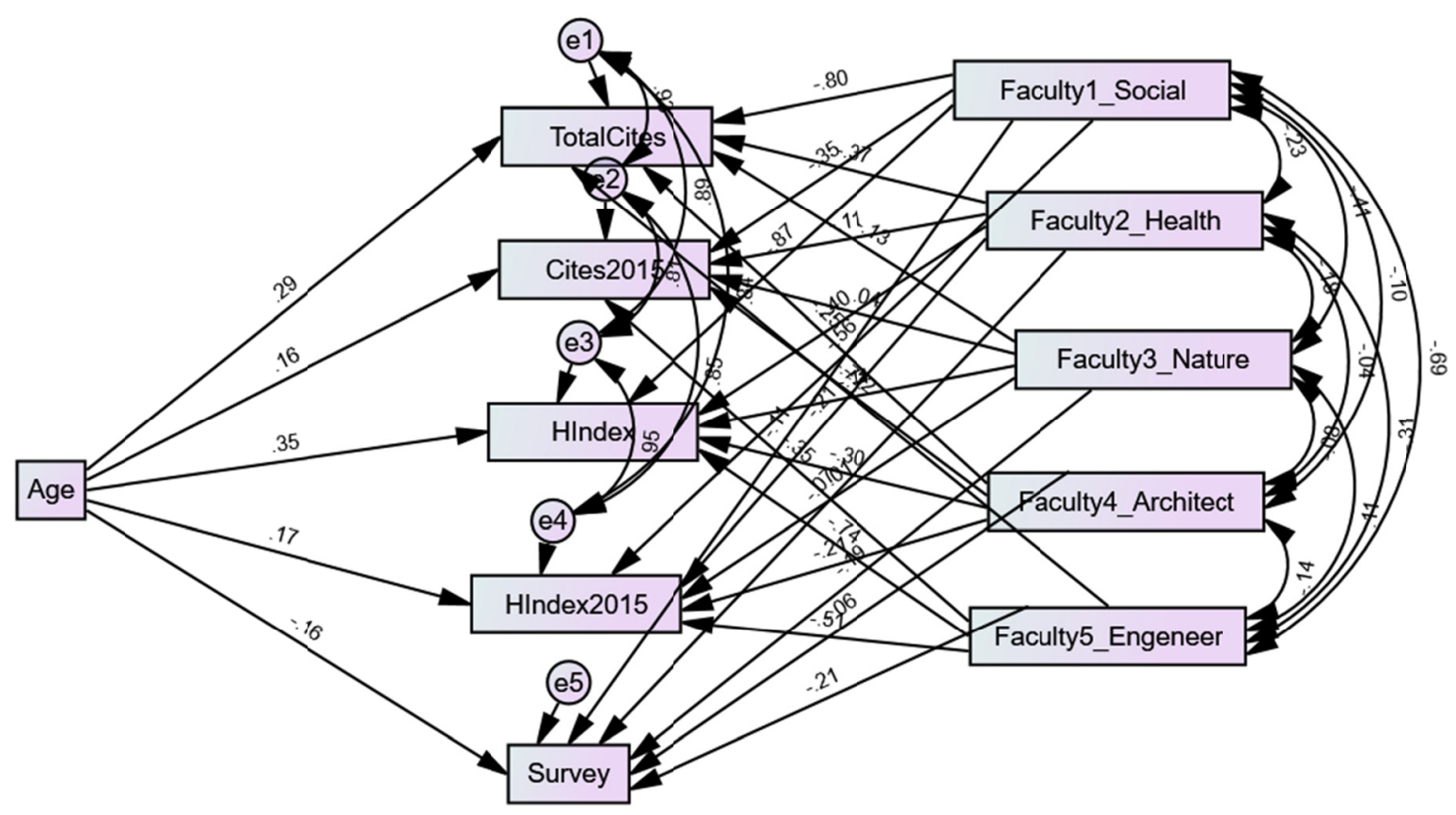

Figure 1. Model path and standardized estimates

The hypothesized model showed a good fit: $\mathrm{CMIN} / \mathrm{DF}=2.6, \mathrm{CFI}=1, \mathrm{RMSEA}=0.07, \mathrm{NFI}=.99, \mathrm{TLI}=.96$. All hypotheses were supported. AGE positively affects TotalCites $(\mathrm{H} 1)(\beta=.30, \mathrm{p}<.001), A G E$ positively affects Cites2015 (H2) $(\beta=.16, \mathrm{p}<.01), A G E$ positively affects HIndex $(\mathrm{H} 3)(\beta=.35, \mathrm{p}<.001), A G E$ positively affects HIndex2015 (H4) $(\beta=.18, \mathrm{p}<.01), A G E$ negatively affects Survey $(\mathrm{H} 5)(\beta=-.16, \mathrm{p}<.01)$. As an example, Figure 2 illustrates the effect of Age on TotalCites.

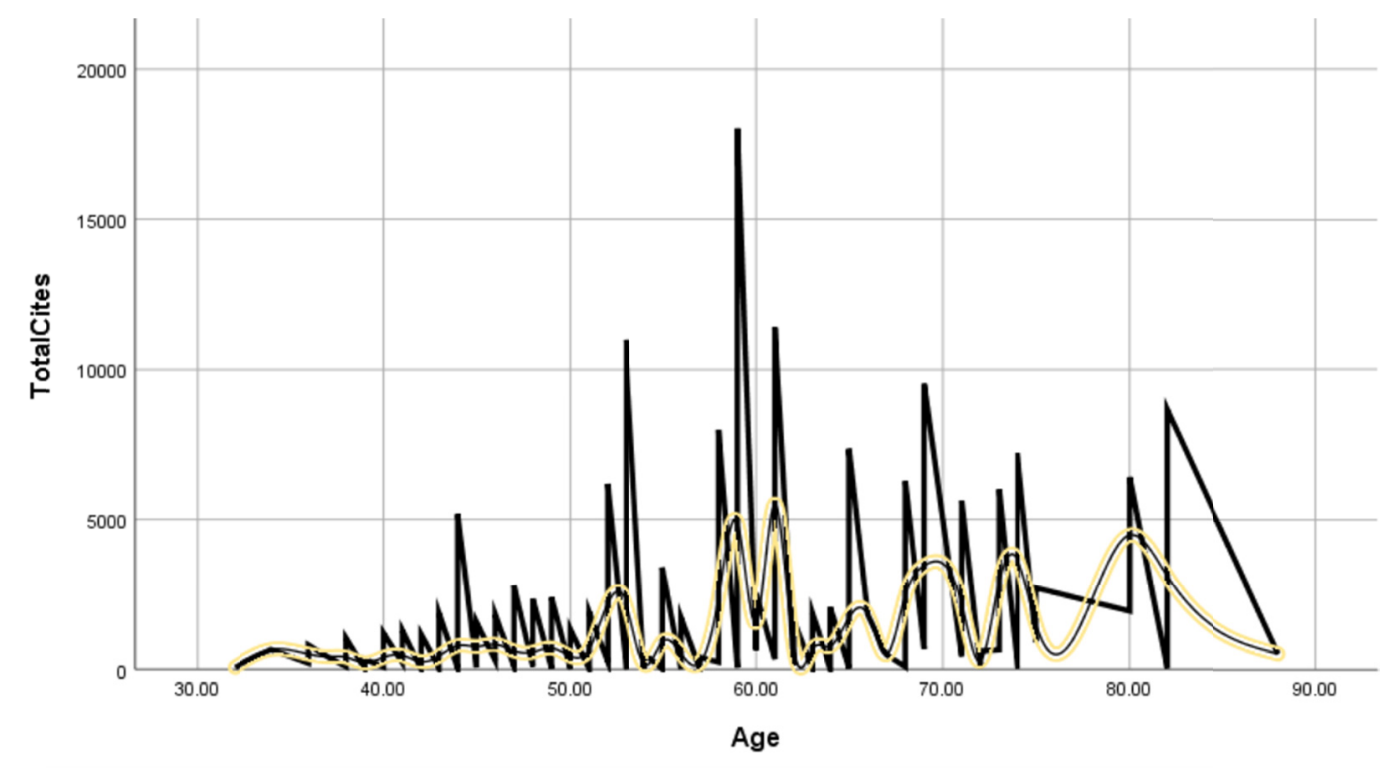

Figure 2. Effect of age on TotalCites

From Figure 2 we observe the curve interpolation line, which displays a general increase in citations with age.

\subsection{Sensitivity Analysis}

In the next step, we explored three major age groups in order to investigate their effect on productivity, measured 
by citations. We divided the faculty staff into three age groups. 32-50, 51-66, and 67-88. The rationale of this division is that 67 is the retirement age in Israel (Eckhaus \& Davidovitch, 2019a) and the typical age for receiving the rank of senior lecturer is around $45-50$.

Before developing the composite model with the controlled variables, since it is not possible to place the three groups together in the model as this would result in a saturated model, we first developed four linear regressions where the independent variables are the three age groups and the dependent variables are each of the citation variables per regression, respectively, in order to receive an initial general idea (Table 1).

Table 1. Regressions of the effect of the age groups on the citation variables

\begin{tabular}{lllllll}
\hline & Coefficients $(B)$ & Statistical error $(S E)$ & Weight $(\beta)$ & $R^{2}$ & $\Delta R^{2}$ & Dependent \\
\hline Age Group 2 & 376.82 & 131.71 & $.19^{* *}$ & .04 & $.03^{* *}$ & Cites2015 \\
Age Group 3 & 390.98 & 182.07 & $.14^{*}$ & & & \\
Age Group 2 & 966.04 & 282.18 & $.22^{* * *}$ & .10 & $.09^{* * *}$ & TotalCites \\
Age Group 3 & 1852.12 & 385.96 & $.30^{* * *}$ & & & \\
Age Group 2 & 3.99 & 1.34 & $.18^{* *}$ & .12 & $.12^{* * *}$ & HIndex \\
Age Group 3 & 10.82 & 1.85 & $.36^{* * *}$ & & & \\
Age Group 2 & 1.63 & .90 & $.12+$ & .03 & $.03^{*}$ & HIndex2015 \\
Age Group 3 & 3.46 & 1.24 & $.18^{*}$ & & & \\
\hline
\end{tabular}

Note. $+\mathrm{p}<.10,{ }^{*} \mathrm{p}<.05, * * \mathrm{p}<.01, * * * \mathrm{p}<.001$.

In Table 1 we observe that only age groups 2 and 3 were included in the regression model. They were both significant in all regressions at a significance level of between .05 and .001 , except for age group 2 which was significant at a slightly higher level. Age group 1 was excluded from all regressions, which means that it has the least effect on the citations when combined with the other two age groups.

Therefore, we next generated the complete model with only age groups 2 and 3 . We place a correlation between the age groups, as they are two sides of the Age variable. Figure 3 illustrates the model and the standardized results.

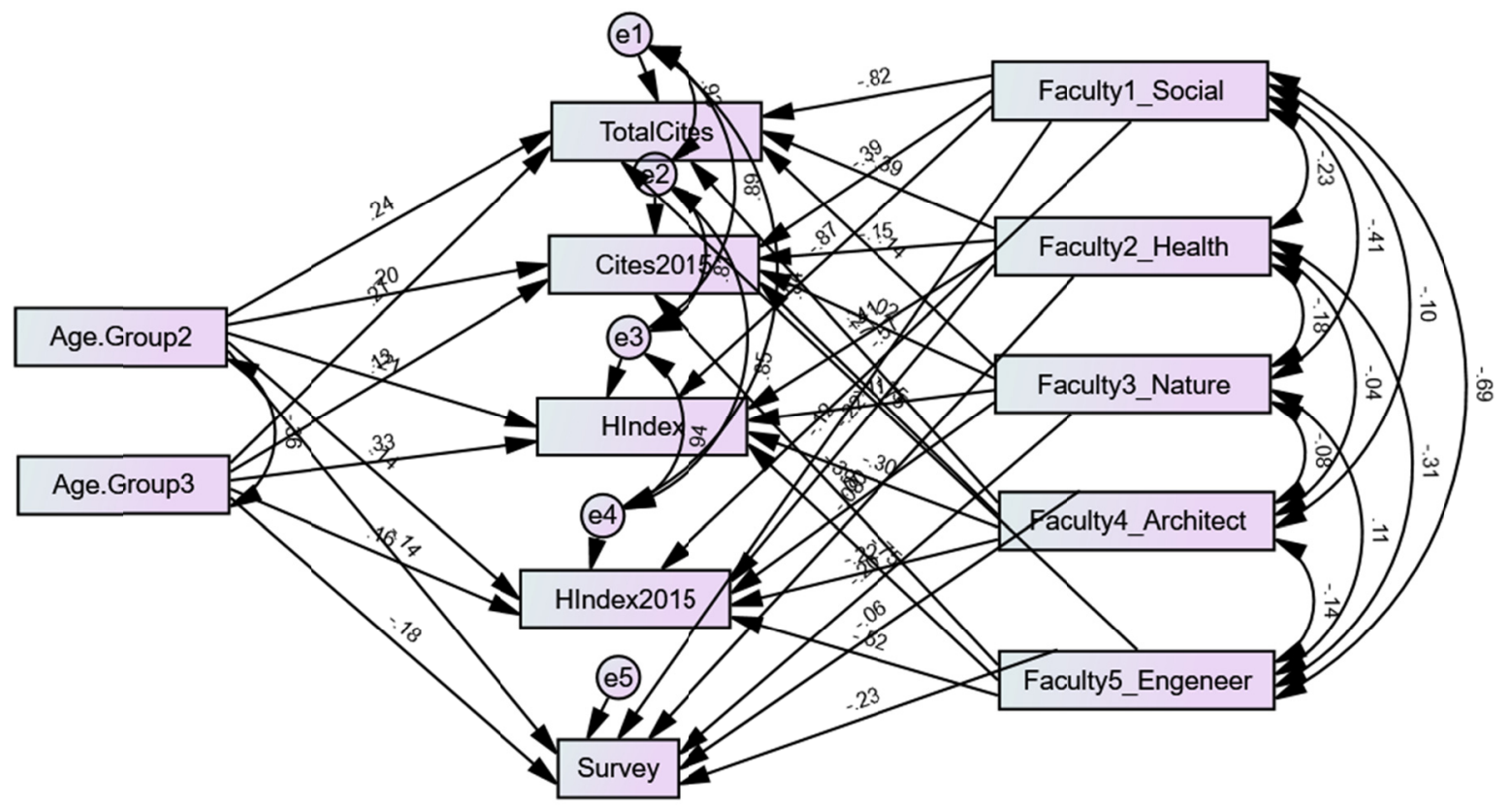

Figure 3. Model and standardized estimates for age groups 2 and 3.

The model showed a good fit: $\mathrm{CMIN} / \mathrm{DF}=2.4, \mathrm{CFI}=.99, \mathrm{RMSEA}=0.066, \mathrm{NFI}=.99, \mathrm{TLI}=.96$. Table 2 presents the estimates and significance levels. 
Table 2. Estimates and significance levels for the effect of age groups 2 and 3

\begin{tabular}{llllll}
\hline & TotalCites & Cites2015 & HIndex & HIndex2015 & Survey \\
\hline Age group 2 & $.24^{* * *}$ & $.20^{* *}$ & $.21^{* * *}$ & $.14^{*}$ & $-.14^{*}$ \\
Age group 3 & $.27 * * *$ & $.13^{*}$ & $.33^{* * *}$ & $.16^{*}$ & $-.18^{* *}$ \\
\hline
\end{tabular}

In Figure 2 and Table 2 we observe a positive effect of age groups 2 and 3 on the citation variables, with a negative effect on the survey score. This result means that in each of the two age groups, the higher the age the higher the citations and the lower the survey score. This matches the results presented in Figure 1.

Finally, we modeled the effect of the youngest age group on the citation variables, controlling for faculty affiliation. Figure 4 illustrates the model and the standardized results, which show an interesting turn.

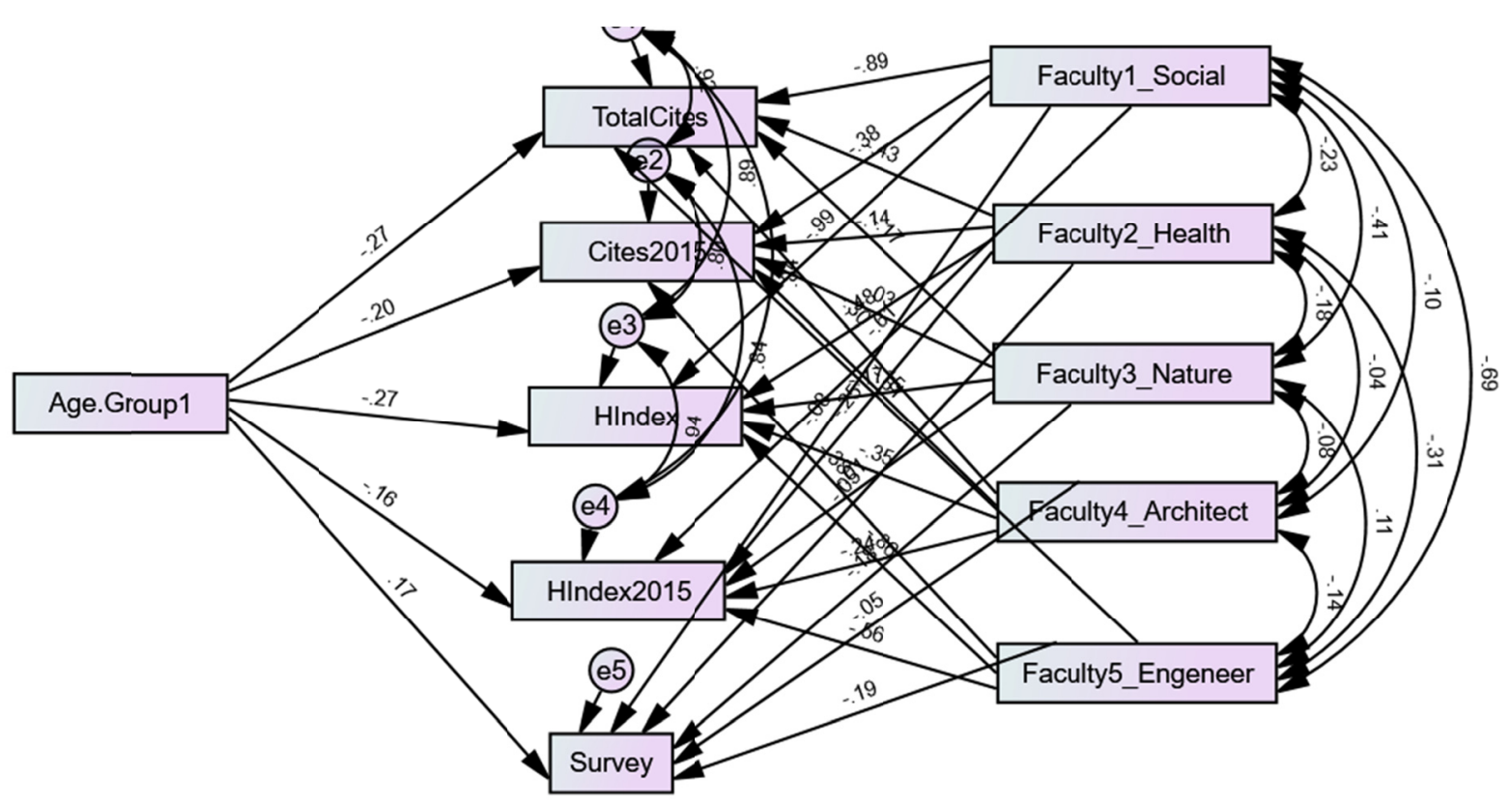

Figure 4. Effect of the youngest age group on the citation variables

The model showed a good fit: $\mathrm{CMIN} / \mathrm{DF}=1.85, \mathrm{CFI}=1, \mathrm{RMSEA}=0.05, \mathrm{NFI}=.99, \mathrm{TLI}=.98$. Table 3 presents the standardized estimates with their significance levels.

Table 3. Estimates and significance levels for the effect of age groups 2 and 3

\begin{tabular}{llllll}
\hline & TotalCites & Cites2015 & HIndex & HIndex2015 & Survey \\
\hline Age group 1 & $-.27^{* * *}$ & $-.20^{* * *}$ & $-.27^{* * *}$ & $-.16^{* *}$ & $.17^{* *}$ \\
\hline
\end{tabular}

In Figure 4 and Table 3 we observe a negative effect of age group 1 on the citation variables, with a positive effect on the survey score. This result means that as the age increases in this age group, citations drop but the survey score increases. As an example, Figure 5 illustrates the minimum values of Total Cites in relation to the age group. Figure 6 illustrates the maximum values of the Survey scores in relation to the age group. Minimum and maximum values are presented respectively for best illustration purposes. 


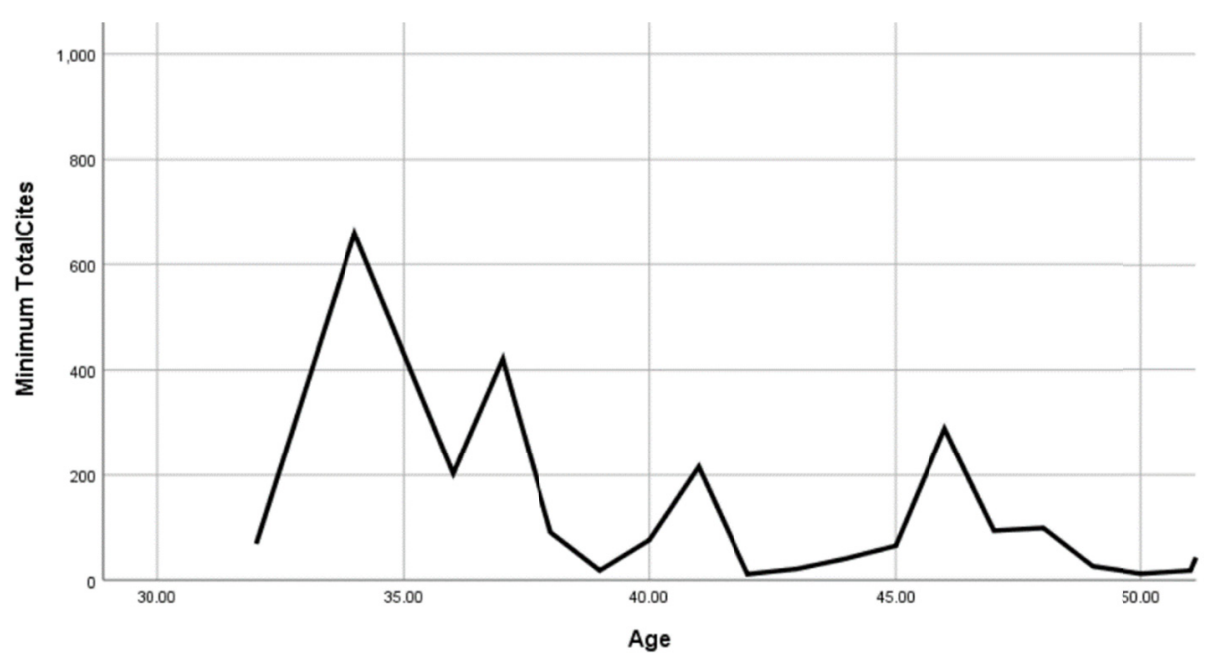

Figure 5. Age group 1 effect on TotalCites

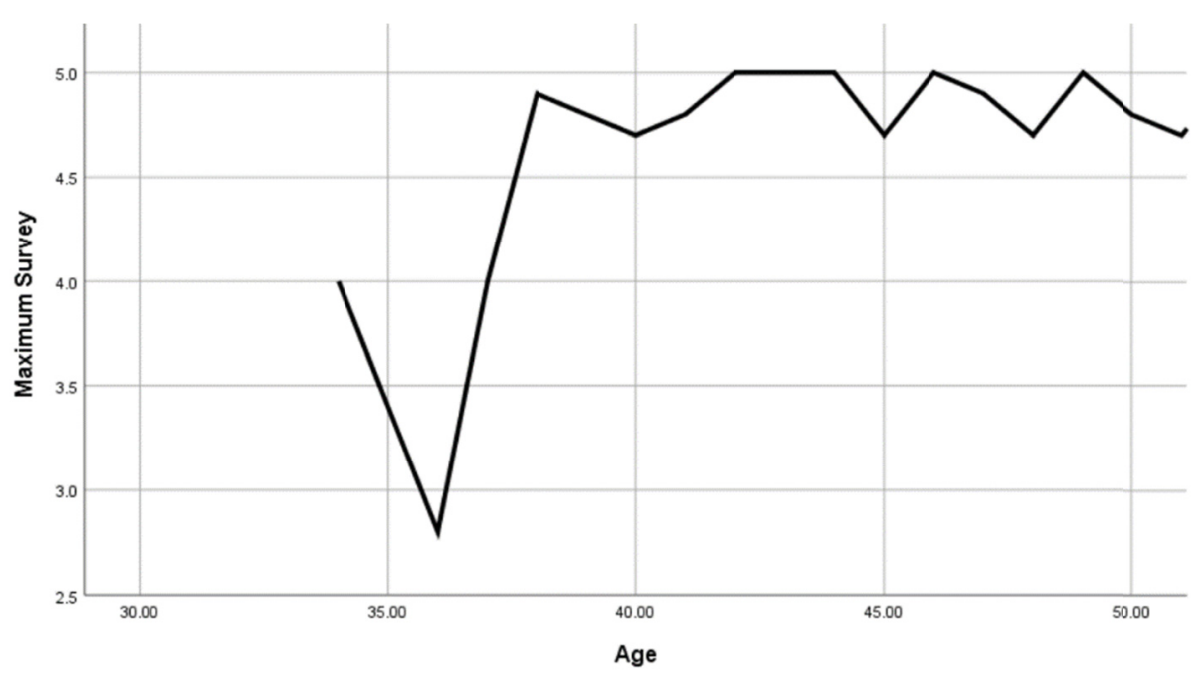

Figure 6. Age group 1 effect on max survey scores values

In Figure 5 we observe the decrease in citations with age, whereas in Figure 6 we observe an increase in the survey scores with age.

\subsection{Effect of Gender on the Number of Citations}

In the following section, we analyze the effect of gender on the number of citations. We constructed a new independent model, since the previous models already hold a relatively large number of variables. Too many variables reduce the model efficiency (Sanche \& Lonergan, 2006), cause the potential of overfitting the data (Ibid), and performance reduction of multiple analyses (Kusuda, Fujimura, Uchiyama, Totsu, \& Matsunami, 2012).

Similar to the previous models, we added faculty affiliation as a control variable. Since there may be a different distribution of males and females in the faculties (Ifeanyi-obi, Olatunji, \& Akpala, 2014; Okunlaya, Amusa, \& Ogunlana, 2015), faculty affiliation was also utilized as a control variable for Gender.

The model showed a good fit (Figure 7): $\mathrm{CMIN} / \mathrm{DF}=1.87, \mathrm{CFI}=1$, RMSEA $=0.05, \mathrm{NFI}=1$, TLI $=.98$. Gender showed a statistically significant correlation with TotalCites $(\beta=.15, \mathrm{p}<.05)$, with HIndex $(\beta=.21, \mathrm{p}<.001)$, and with HIndex $2015(\beta=.15, \mathrm{p}<.05)$. Since gender was defined dichotomously $(0=$ female, $1=$ male $)$, this means that males have more citations than females (H6). There was no statistically significant correlation with Survey scores. 


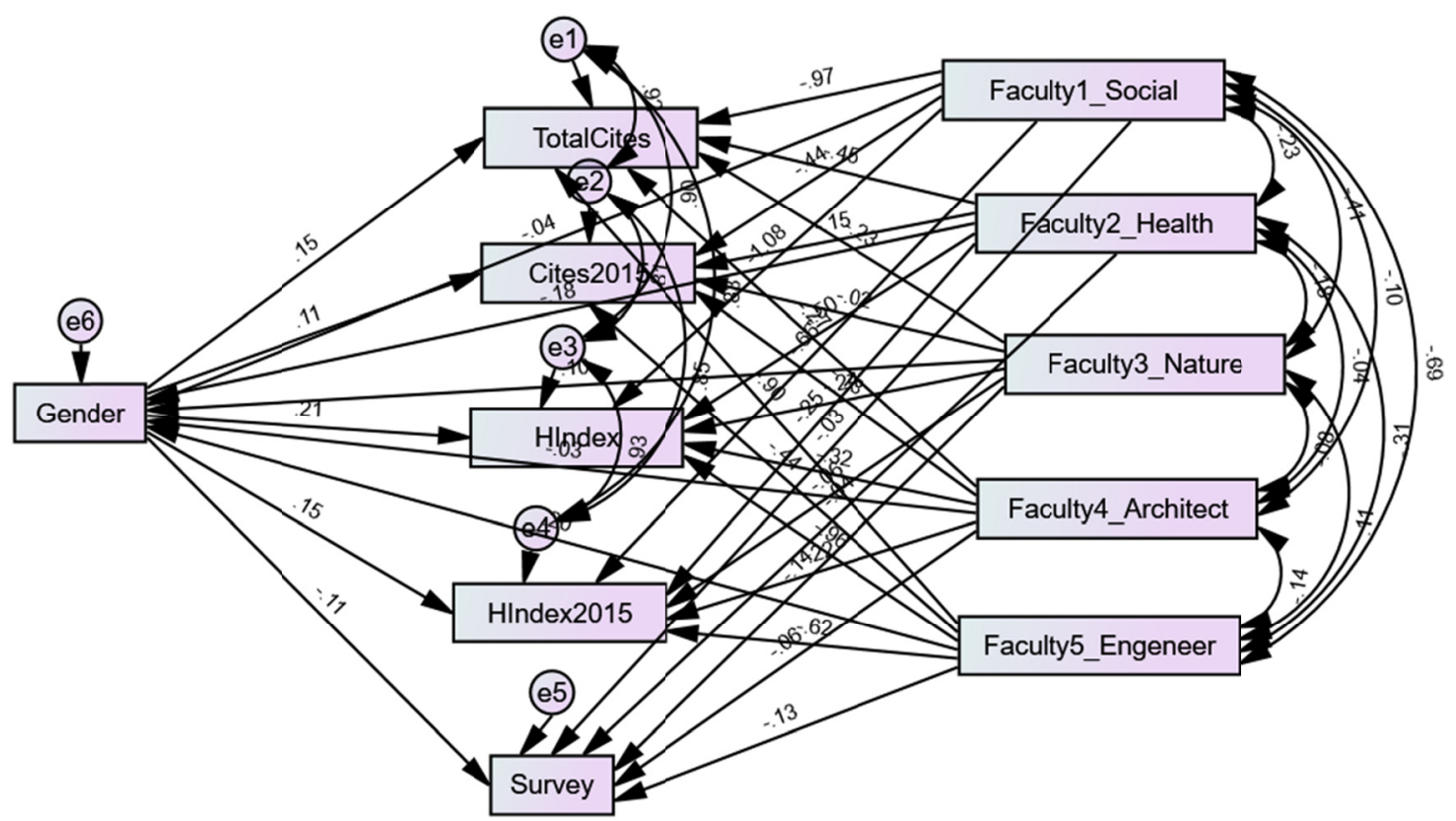

Figure 7. Model and standardized estimates for the effect of gender on the number of citations.

\section{Discussion}

In a single decade, the budget of the higher education system doubled from NIS 6.9 billion in 2010 to NIS 11.8 billion in 2020 (CHE). In 2022 the budget is expected to exceed NIS 12 billion. In addition, during the past decade the number of students has grown significantly. A rise was recorded in the number of women studying in academia. In 2019 women comprised about 59\% of all students. At present, women are the majority of students for all degrees: 58\% in programs for a Bachelor's degree, 63\% in Master's programs, and 53\% in PhD programs.

At the same time, the PBC and the CHE are acting to increase women's representation among academic faculty as well. According to the recommendations of recent committees, a decision was made to grant scholarships to outstanding female post-doctoral students for a sum of up to $\$ 80$ thousand, for female doctoral students in hi-tech disciplines for a sum of NIS 150 thousand, and for female Master's degree students for a sum of NIS 80 thousand. Also, awards totaling approximately one million shekels a year will be granted to institutions who make outstanding efforts to advance and implement gender-related fairness.

We are now in the third decade of the 21st century. Life expectancy has changed and the question is whether demographic measures such as age and gender can affect output and achievements in academia. In academia, a bastion of freedom of creativity and thought, is age a limitation? Can gender be a barrier to scientific achievements? This study addressed the achievements of faculty members in research and teaching as affected by demographic variables of age and gender. We explored their influence on research output by number of citations and satisfaction with teaching as determined by student survey scores.

The research findings indicate that the output of faculty members rises with their age. The opposite is true of teaching evaluations provided by students. Student satisfaction scores with teaching decline with age. Sensitivity analysis shows that in the distribution to age groups $(32-50,51-66,67-88)$, the two older age groups have the highest impact on number of citations. Moreover, the coefficient of the oldest group, the retirees, is higher than that of the middle group, indicating the highest effect. This is also true of the surveys, namely, older age was negatively correlated with survey scores, higher than the other group.

The sensitivity analysis also shows that the number of citations drops with age but survey scores rise. It is to be assumed that the youngest age group, in which not all members are tenured, are under pressure by the institution regarding teaching surveys. Lacking employment security, faculty members are interested in demonstrating the immediate value of their teaching - as manifested by student satisfaction, including preparation of materials for new courses. Teaching, particularly if one strives for meaningful teaching, requires resources, which might come at the expense of research output. Teaching students to think (Davidovitch \& Eckhaus, 2019) is not an easy task. With regard to gender, gender was found to affect the number of research citations, which is higher among men 
than among women. In conclusion, the achievements of academic faculty members are certainly age-dependent: seniority and experience contribute to research (number of citations) but not to teaching as measured by student satisfaction.

The research findings may have practical implications for the ability to breach age and gender barriers in academia. How can the limitation of employment age in academia be breached in the modern era, when quality of life and life expectancy are on the rise-particularly for "high academic producers", in light of their achievements? How can a support net be formed for women in order to facilitate their academic achievements? Is there room to raise the retirement age for "information producing" faculty members? Is there room to form a support net that includes mentoring and research collaborations, such that senior staff, who are older and have more experience, will provide assistance to "academic novices"? And with regard to teaching - how can seniority and experience be utilized to advance teaching, both through technology and as supervisors of students for advanced degrees - together with "academic novices"?

Indeed, it is necessary to take action aimed at breaching barriers - but it is possible that the solution will not be generated by committees that have already been formed while the phenomenon still exists. Perhaps the solution will come from faculty members who will strive to express their achievements, unrelated to age and gender, and will take action towards this end. The current decade was characterized by excellence and by a great flourishing of the academic system. The large budgets allowed the system to expand accessibility programs and to open the gates of academia to all population groups. There is a significant increase in investments in research, funds, and infrastructure, as well as in flagship issues: data science and artificial intelligence, personally adapted medicine, and quantum science and technology. Furthermore, the number of academic publications has risen, and thanks to the national program for promoting hi-tech subjects engineering studies are now the most popular course of studies in Israel. The digital academic learning revolution is in its midst and, for the first time, the system is promoting entrepreneurship and innovativeness studies and opening academia to collaborations with industry.

This is the time to breach the limitations of age - to allow those with experience and seniority to continue operating together with the young academic forces, and to enable women to take part in leading and participating in the challenges of the future.

Finally, the research is based on a case study of one university. Future research may extend the currest study by comparing and investigating other types of institutions, such as colleges and even professional oriented institutions.

\section{References}

Ayres, I., \& Vars, F. E. (2000). Determinants of citations to articles in elite law reviews. The Journal of Legal Studies, 29(S1), 427-450. https://doi.org/10.1086/468081

Borsuk, R. M., Budden, A. E., Leimu, R., Aarssen, L. W., \& Lortie, C. J. (2009). The influence of author gender, national language and number of authors on citation rate in ecology. The Open Ecology Journal, 2(1), 25-28. https://doi.org/10.2174/1874213000902010025

Caplar, N., Tacchella, S., \& Birrer, S. (2017). Quantitative evaluation of gender bias in astronomical publications from citation counts. Nature Astronomy, 1(6), 1-5. https://doi.org/10.1038/s41550-017-0141

Carter, T. E., Smith, T. E., \& Osteen, P. J. (2017). Gender comparisons of social work faculty using h-index scores. Scientometrics, 111(3), 1547-1557. https://doi.org/10.1007/s11192-017-2287-0

Chan, D. K., Lonsdale, C., Ho, P. Y., Yung, P. S., \& Chan, K. M. (2009). Patient motivation and adherence to post surgery rehabilitation exercise recommendations: The influence of physiotherapists' autonomy-supportive behaviors. Archives of Physical Medicine and Rehabilitation, 90(12), 1977-1982. https://doi.org/10.1016/j.apmr.2009.05.024

CHE. (2015). Report of the committee for the advancement and representation of women at institutions of higher education. $\quad$ CHE Website. Jerusalem. $\quad$ Retrieved from https://che.org.il/wp-content/uploads/2015/07/\%d7\%93\%d7\%95\%d7\%97-\%d7\%99\%d7\%99\%d7\%a6\%d7 $\% 95 \% \mathrm{~d} 7 \% 92-\% \mathrm{~d} 7 \% \mathrm{a} 0 \% \mathrm{~d} 7 \% \mathrm{a} 9 \% \mathrm{~d} 7 \% 99 \% \mathrm{~d} 7 \% 9 \mathrm{~d} . p d f$ [Hebrew]

Davidovitch, N., \& Eckhaus, E. (2019). Teaching students to think-faculty recommendations for teaching evaluations employing automated content analysis. International Journal of Higher Education, 8(3), 83-93. https://doi.org/10.5430/ijhe.v8n3p83

Davidovitch, N., \& Eckhaus, E. (2020). Senior faculty opinions on the significance of retirement age-Employing natural language processing. Higher Education Studies, 10(2), 38-44. 
https://doi.org/10.5539/hes.v10n2p38

Eckhaus, E. (2019a). Happiness in fashion. In J. Kantola, S. Nazir \& T. Barath (Eds.), Advances in Human Factors, Business Management and Society (vol. 783, pp. 15-25). AHFE 2018. Advances in Intelligent Systems and Computing. Cham: Springer International Publishing.

Eckhaus, E. (2019b). How to be happy. Blog section onhttp://www.artistila.com/. Retrieved from http://www.artistila.com/how-to-by-happy/

Eckhaus, E., \& Davidovitch, N. (2019a). Effect of personal and occupational characteristics on attitudes to an obligatory retirement age-A content analysis investigation. Journal of Education and Learning, 8(6), 169-179. https://doi.org/10.5539/jel.v8n6p169

Eckhaus, E., \& Davidovitch, N. (2019b). How do academic faculty members perceive the effect of teaching surveys completed by students on appointment and promotion processes at academic institutions? A case study. International Journal of Higher Education, 8(1), 171-180. https://doi.org/10.5430/ijhe.v8n1p171

Eckhaus, E., \& Davidovitch, N. (2019c). Potential for blocking advancement: Teaching surveys for student evaluation of lecturers. International Journal of Educational Methodology, 5(3), 401-406. https://doi.org/10.12973/ijem.5.3.401

Eckhaus, E., \& Sheaffer, Z. (2019). Factors affecting willingness to contribute goods and services on social media. The Social Science Journal, 56(3), 390-400. https://doi.org/10.1016/j.soscij.2018.08.001

Geraci, L., Balsis, S., \& Busch, A. J. B. (2015). Gender and the h-index in psychology. Scientometrics, 105(3), 2023-2034. https://doi.org/10.1007/s11192-015-1757-5

Ifeanyi-obi, C., Olatunji, S., \& Akpala, J. (2014). Perceived effects of Facebook on academic activities of agricultural students in the Universityof Port Harcourt. IOSR Journal of Mobile Computing and Application, $1(2), 12-16$.

Jadidi, M., Karimi, F., Lietz, H., \& Wagner, C. (2018). Gender disparities in science? Dropout, productivity, collaborations and success of male and female computer scientists. Advances in Complex Systems, 21(03n04), 1750011. https://doi.org/10.1142/S0219525917500114

Jones, B. F. (2010). Age and great invention. The Review of Economics and Statistics, 92(1), 1-14. https://doi.org/10.1162/rest.2009.11724

Kang, J., \& Hustvedt, G. (2014). Building trust between consumers and corporations: The role of consumer perceptions of transparency and social responsibility. Journal of Business Ethics, 125(2), 253-265. https://doi.org/10.1007/s10551-013-1916-7

Kusuda, S., Fujimura, M., Uchiyama, A., Totsu, S., \& Matsunami, K. (2012). Trends in morbidity and mortality among very-low-birth-weight infants from 2003 to 2008 in Japan. Pediatric Research, 72(5), 531-538. https://doi.org/10.1038/pr.2012.114

Lerer, M., \& Avgar, I. (2018). Representation of women in the Israeli academia. Jerusalem: The Knesset Research and Information Center. [Hebrew]

Levy, I., \& Eckhaus, E. (2020). Rape narratives analysis through natural language processing: Survivor self-label, narrative time span, faith, and rape terminology. Psychological Trauma: Theory, Research, Practice and Policy, 12(6), 635-642. https://doi.org/10.1037/tra0000587

Liau, Y. W., Cheow, C., Leung, K. T. Y., Tan, H., Low, S. F., Cheen, H. H. M., ... Lee, E. S. (2019). A cultural adaptation and validation study of a self-report measure of the extent of and reasons for medication nonadherence among patients with diabetes in Singapore. Patient Preference and Adherence, 13, 1241. https://doi.org/10.2147/PPA.S208736

Mueller, C. M., Gaudilliere, D. K., Kin, C., Menorca, R., \& Girod, S. (2016). Gender disparities in scholarly productivity of US academic surgeons. Journal of Surgical Research, 203(1), 28-33. https://doi.org/10.1016/j.jss.2016.03.060

Nosek, B. A., Graham, J., Lindner, N. M., Kesebir, S., Hawkins, C. B., Hahn, C., ... Frazier, R. (2010). Cumulative and career-stage citation impact of social-personality psychology programs and their members.

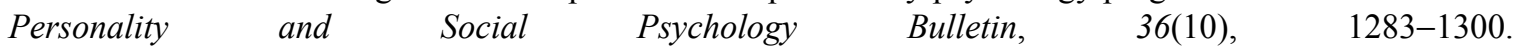
https://doi.org/10.1177/0146167210378111

Okunlaya, R., Amusa, O. I., \& Ogunlana, K. (2015). Prospects and challenges of internet use among the 
postgraduate students of social and management sciences in Olabisi Onabanjo University, Nigeria. Prospects, 5(5).

Sanche, R., \& Lonergan, K. (2006). Variable reduction for predictive modeling with clustering. Paper presented at the Casualty Actuarial Society Forum.

Seidman, G. (2015). What do lecturers do when they are not teaching? Mishpat Va'asakim, 19, 1447-1621. Retrieved from http://portal.idc.ac.il/he/lawreview/volumes/19/documents/seidman.pdf [Hebrew]

Tomei, K. L., Nahass, M. M., Husain, Q., Agarwal, N., Patel, S. K., Svider, P. F., ... Liu, J. K. (2014). A gender-based comparison of academic rank and scholarly productivity in academic neurological surgery. Journal of Clinical Neuroscience, 21(7), 1102-1105. https://doi.org/10.1016/j.jocn.2013.11.006

Yang, H. Y., Rhee, G., Xuan, L., Silver, J. K., Jalal, S., \& Khosa, F. (2019). Analysis of H-index in assessing gender differences in academic rank and leadership in physical medicine and rehabilitation in the United States and Canada. American Journal of Physical Medicine \& Rehabilitation, 98(6), 479-483. https://doi.org/10.1097/PHM.0000000000001129

\section{Copyrights}

Copyright for this article is retained by the author, with first publication rights granted to the journal.

This is an open-access article distributed under the terms and conditions of the Creative Commons Attribution license (http://creativecommons.org/licenses/by/4.0/). 